\title{
Klasifikasi Aktivitas Manusia menggunakan metode Ensemble Stacking berbasis Smartphone
}

\author{
Firman Aziz \\ Fakultas Matematika dan Ilmu Pengetahuan Alam, Universitas Pancasakti \\ Universitas Pancasakti \\ Makassar, Indonesia \\ Firman.aziz@unpacti.ac.id
}

\begin{abstract}
Abstrak
Dengan perkembangan teknologi yang semakin pesat, kini smartphone dapat mengenali aktivitas manusia menggunakan sensor accelerometer dan gyroscope yang telah tertanam didalamnya dengan menghasilkan ratusan bahkan ribuan record dan membutuhkan metode data mining untuk melakukan pengelompokkan berdasarkan output tersebut. Metode data mining yang memiliki kinerja lebih baik dibandingkan metode lainnya adalah SVM tetapi sensitif terhadap parameter setting dan training sample yang menyebabkan performa tidak maksimal maka ensemble adalah solusinya. Penelitian ini mengusulkan penerapan metode ensemble Stacking untuk melakukan klasifikasi aktivitas manusia berbasis sensor accelerometer dan gyroscope. Hasil menunjukkan kinerja ensemble Stacking dengan akurasi $99.2 \%$, sensitivity $99.6 \%$ dan specificity $98.7 \%$.
\end{abstract}

Kata Kunci: Klasifikasi, Accelerometer, Gyroscope, SVM, Ensemble Stacking.

\begin{abstract}
With the rapid development of technology, now the sophistication of cellphones can identify human activities using sensors that have been embedded in them by producing data records. The resulting data output will be grouped using machine learning. One method with better performance than other methods is SVM, but it is sensitive to setting parameters and training samples that cause performance to be not optimal, so ensemble is the solution. This research proposes using the ensemble stacking method to classify human activities based on accelerometer and gyroscope sensors. The results show the ensemble stacking has an accuracy of $99.2 \%$, a sensitivity of $99.6 \%$, and $98.7 \%$ specificity.
\end{abstract}

Keywords: Classification, Accelerometer, Gyroscope, SVM, Ensemble Stacking.

\section{Pendahuluan}

Human Activity Recognition merupakan teknologi pengenalan aktivitas manusia yang memungkinkan sebuah sistem mendeteksi aktivitas sederhana yang dilakukan manusia, seperti duduk, berdiri, berjalan, berlari, melompat, naik tangga, turun tangga dan lain-lain menggunakan kamera ataupun sensor. Seiring perkembangan teknologi yang semakin pesat, aktivitas manusia dapat diidentifikasi menggunakan sensor accelerometer dan gyroscope yang telah tertanam pada smartphone ( $\mathrm{Su}$, Xing, Hanghang Tong, and Ping Ji).

Sensor accelerometer dan gyroscope menghasilkan ratusan bahkan ribuan record dan membutuhkan sebuah metode data mining yang dapat mengelompokkan aktivitas manusia berdasarkan output tersebut. Data mining merupakan pencarian pola melalui proses komputasi pada kumpulan data menggunakan metode seperti kecerdasan buatan, pembelajaran mesin, statistik dll (Chen, Ming-Syan, Jiawei Han, and Philip S. Yu).

Penelitian (Kaghyan, Sahak, and Hakob Sarukhanyan), melakukan clustering menggunakan algoritma K-Means dengan memanfaatkan sensor accelerometer dan gyroscope 
pada smartphone untuk mengidentifikasi berbagai aktivitas manusia seperti; duduk, berdiri, berjalan dan berlari. Untuk mengidentifikasi aktivitas manusia dibutuhkan data yang diambil menggunakan sensor di letakkan pada bagian tubuh yang melakukan pergerakan. Penelitian (Putra, Suryadi, Istianah Muslim, and Muhammad Ihsan Zul), mengolah data gambar berupa citra yang diproses untuk mengidentifikasi aktivitas manusia. Metode pengenalan aktivitas manusia berbasis citra mempunyai kekurangan yaitu tidak adaptif terhadap cahaya, sehingga akurasi sistem menurun apabila pencahayaan ruangan gelap ataupun terang. Penelitian (Zubair, Muhammad, Kibong Song, and Changwoo Yoon), menempatkan sensor accelerometer pada empat bagian tubuh yaitu pinggang, paha kiri, pergelangan kaki kanan dan lengan kanan untuk mengklasifikasi aktivitas manusia. Metode random forest dan decision tree digunakan sebagai klasifikasi tetapi kedua metode tersebut membutuhkan waktu komputasi yang lama. Penelitian (Agus Setiyandi), melakukan penerapan algoritma K-Means menggunakan aplikasi HumanMove dalam pengenalan pergerakan aktivitas manusia. Hasil menunjukkan aplikasi dianggap berhasil mengenali aktivitas manusia tetapi penelitian ini hanya membaca data dari sensor accelerometer dan gyroscope sesuai dengan aktivitas yang dilakukan dan tidak melakukan uji performa dalam hal keakuratan algoritma yang diusulkan. Penelitian (Rahmah, Fadhilatur, Hurriyatul Fitriyah, and Issa Arwani) mengidentifikasi aktivitas manusia menggunakan sensor accelerometer dan gyroscope pada lima bagian tubuh yaitu kepala, lengan, pinggang, paha dan kaki bagian bawah. Metode klasifikasi menggunakan metode k-Nearest Neighbor. Hasil menunjukkan bahwa akurasi tertinggi sebesar 93,75\% untuk posisi sensor berada di paha. Sedangkan akurasi terendah sebesar 53,75\% dengan posisi sensor berada di kepala. Penelitian (Hardiyanti, Nurul, Armin Lawi, and Firman Aziz) mengusulkan penerapan teknik ensemble svm untuk melakukan klasifikasi aktivitas manusia berdasarkan sensor accelerometer dan gyroscope. Hasil menunjukkan teknik ensemble SVM memiliki performansi terbaik ketika partisi data $70 \%$ data latih dan 30\% data uji dengan akurasi 99,1\%, sensitivitas 99,6\% dan spesifisitas 98,7\%. Penelitian (Lawi, A., F. Aziz, and S. L. Wungo) mengusulkan penerapan metode ensemble gradientboost untuk mengklasifikasikan naik dan turun tangga. Dataset dipartisi menjadi $70 \%$ data latih dan $30 \%$ data uji. Hasil penelitian menunjukkan bahwa kinerja metode ensemble gradientboost menghasilkan mencapai akurasi 81,82\%, sensitivitas 86,11\%, dan spesifisitas $77,50 \%$.

Penelitian ini mengusulkan klasifikasi aktivitas manusia berbasis sensor accelerometer dan gyroscope yang dipasang pada paha manusia menggunakan metode Support Vector Machine karena memiliki kinerja terbaik berdasarkan penelitian sebelunya. Data dipartisi menjadi $70 \%$ data latih dan $30 \%$ data uji. Berbeda dengan penelitian ensemble lainnya, penelitian ini menerapkan metode ensemble Stacking untuk melihat peningkatan kinerja metode Support Vector Machine.

\section{Kajian Pustaka}

\subsection{Sensor Accelerometer}

Accelerometer adalah perangkat yang berfungsi untuk mengukur akselerasi tepat. Accelerometer tidak memiliki ketepatan koordinat (laju perubahan velocity) saat mengukur akselerasi tepat (Tinder, Richard F). Tetapi Accelerometer mengidentifikasi akselerasi terkait dengan fenomena berat yang dialami oleh massa uji pada kerangka acuan perangkat akselerometer (Rindler, Wolfgang).

Sensor Accelerometer pada smartphone berfungsi untuk menentukan derajat kemiringan dari smartphone yang melakukan pembacaan tiga sumbu dari arah yang berbeda. Gambar 1 . Ilustrasi sensor accelerometer pada smartphone. 
Vol. 2 No. 1 Januari 2021

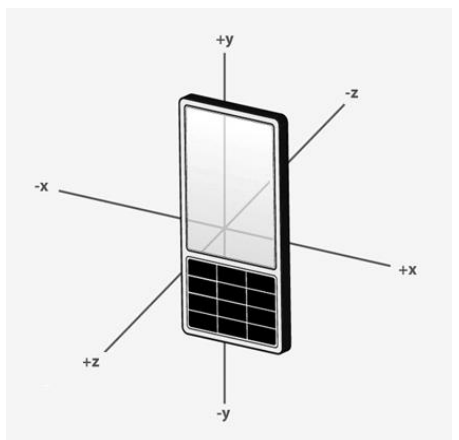

Gambar 1. Ilustrasi sensor accelerometer pada smartphone.

\subsection{Sensor Accelerometer}

Giroskop adalah perangkat untuk mengukur atau mempertahankan orientasi, yang berlandaskan pada prinsip-prinsip momentum sudut (Kabai, Sandor). gyroscope memiliki prinsip kerja apabila berotasi searah dengan jarum jam pada sumbu $\mathrm{Z}$ maka tegangan output yang dihasilkan akan mengecil (-Z), sedangkan apabila berotasi melawan arah dengan jarum jam pada sumbu $\mathrm{Z}$ maka tegangan output yang dihasilkan akan membesar $(+Z)$ dan saat tidak berotasi atau berada pada keadaan diam maka tegangan outputnya akan sesuai dengan nilai offset gyrosensor tersebut. Gambar 2. Menunjukkan ilustrasi sensor gyroscope pada smartphone.

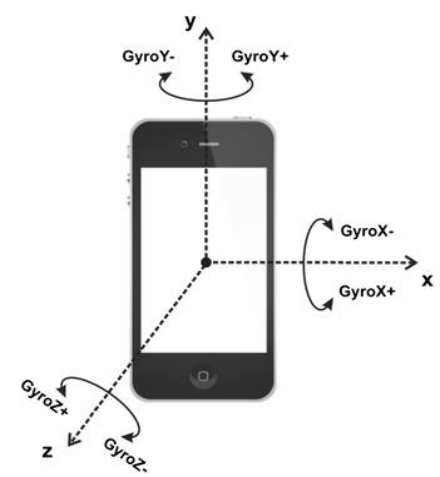

Gambar 2. Ilustrasi sensor gyroscope pada smartphone.

\subsection{Support Vector Machine}

SVM merupakan salah satu metode dalam masalah klasifikasi pola. SVM telah berkembang sejak tahun 1960-an, tetapi baru diperkenalkan oleh Vapnik pada tahun 1995 (Cortes, Corinna, and Vladimir Vapnik). SVM menemukan hyperplane optimal yang mengkategorikan input data pelatihan ke dalam kelas. Gambar 3. menunjukkan basic dari SVM.

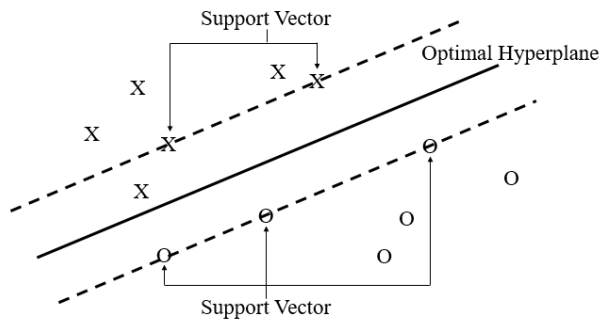

Gambar 3. Basic dari Support Vector Machine. 


\subsection{Metode Ensemble Stacking}

Metode ensemble adalah penggabungan beberapa set model yang menyelesaikan suatu masalah untuk mendapatkan suatu model yang lebih akurat. Metode ensemble secara efektif dapat mengurangi kesalahan klasifikasi dan mampu meningkatkan kinerja classifier tunggal (Polikar, Robi). berbeda dengan classifier tunggal yang hanya belajar dan melatih satu set data saja, ensemble classifiers belajar dan melatih beragam kumpulan data asli, kemudian hasilnya akan membangun satu set hipotesis dari data yang dilatih (Kuncheva, Ludmila I).

Stacking merupakan kombinasi beberapa model dari tipe yang berbeda menggunakan konsep meta-learner. Train learner pertama menggunakan kumpulan data training asli untuk menghasilkan kumpulan data baru yang digunakan kembali untuk melatih learner tingkat kedua. Output learner pertama merupakan fitur masukan sementara label asli masih dianggap sebagai label data training baru. Pembelajar tingkat pertama sering dihasilkan dengan menerapkan algoritma learning yang berbeda (Wolpert, David $H$ ).

\subsection{Evaluasi Kinerja}

Evaluasi kinerja dari metode klasifikasi dapat dilihat dari tingkat kesalahan klasifikasinya. Untuk menghitung nilai kesalahan klasifikasi dapat menggunakan confusion matrix (Provost, Foster, and Ron Kohavi).

Tabel 1. Confusion Matrix.

\begin{tabular}{lll}
\hline Aktual/Prediksi & Berjalan & Berlari \\
\hline Berjalan & TP & FN \\
Berlari & FP & TN \\
\hline
\end{tabular}

Kinerja setiap klasifikasi dievaluasi berdasarkan Akurasi, Sensitivitas, dan Spesifitas. Pengukuran menggunakan persamaan sebagai berikut:

$$
\begin{aligned}
& \text { Akurasi }=\frac{T P+T N}{T N+F P+F N+T P} \\
& \text { Sensitivitas }=\frac{T P}{T P+F N} \\
& \text { Spesifisitas }=\frac{T N}{T N+F P}
\end{aligned}
$$

\section{Perancangan Sistem/Metode Penelitian}

Dalam penelitian ini, data diambil dengan sensor accelerometer dan gyroscope yang telah tertanam pada smartphone menggunakan system berbasis android yang telah dirancang untuk membaca sensor tersebut. Smartphone android diletakkan pada bagian kaki kanan manusia dengan durasi waktu \pm 12 detik. Data sensor accelerometer dan gyroscope akan secara otomatis tersimpan diruang penyimpanan smartphone dengan format *.xls (jalan=0, lari $=1$ ). Data berupa koordinat $\mathrm{x}, \mathrm{y}, \mathrm{z}$ dari sensor accelerometer dan gyroscope. Data terdiri dari 6 atribut sebagai berikut : Accelerometer sumbu x, Accelerometer sumbu y, Accelerometer sumbu z, Gyroscope sumbu x, Gyroscope sumbu y, dan Gyroscope sumbu z.

Proses reduksi data dilakukan dengan mengurangi ukuran kumpulan data untuk mencapai representasi kelas yang sama antara kelas 'Berjalan' dan 'Berlari' sehingga total data 
sebanyak 3600 record dengan perwakilan masing-masing kelas sebanyak 1800. Kemudian data akan dipartisi menjadi $70 \%$ data latih dan 30\% data uji dari total keseluruhan record.

\section{Implementasi Sistem dan Hasil}

Pada bagian ini, keseluruhan hasil diperoleh dari eksperimen menggunakan Bahasa pemprograman python 2.7. Tabel 2 menunjukkan kinerja dari SVM dan ensemble Stacking.

Tabel 2. Confusion Matrix.

\begin{tabular}{llll}
\hline Metode & Akurasi & Sensitivitas & Spesifisitas \\
\hline SVM & 98.8 & 98.3 & 99.3 \\
Ensemble Stacking & 99.2 & 99.6 & 98.7 \\
\hline
\end{tabular}

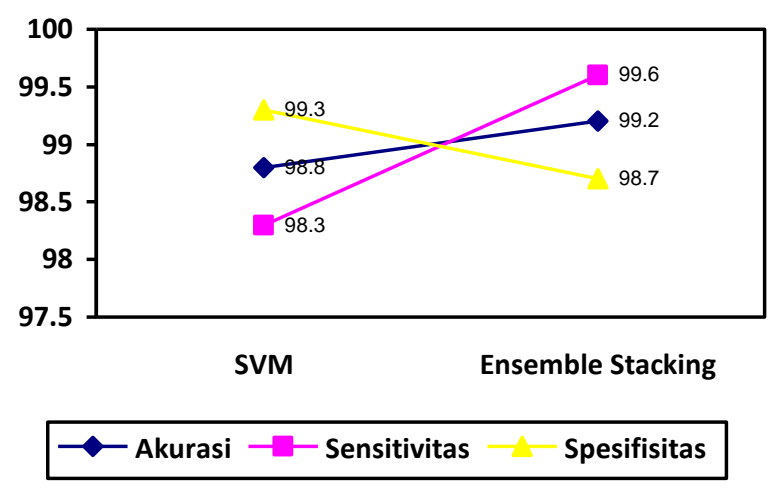

Gambar 4. Perbandingan hasil kinerja metode.

Pengukuran akurasi dan sensitivitas yang tinggi serta pengukuran spesifisitas yang rendah sangat dibutuhkan untuk mendeteksi aktivitas manusia. Gambar 4. Menunjukkan akurasi dari kedua algoritma yang diusulkan dimana dengan melakukan ensemble Stacking dengan Support Vector Machine berhasil meningkatkan akurasi dan sensitivitas serta menurunkan spesifisitas dari Support Vector Machine tunggal. Peningkatan akurasi metode ensemble Stacking dengan Support Vector Machine sebesar 0.4\%, peningkatan sensitivitas sebesar $1.3 \%$ dan penurunan spesifisitas sebesar $0.6 \%$.

\section{Kesimpulan}

Penelitian ini mengusulkan klasifikasi aktivitas manusia menggunakan sensor accelerometer dan gyroscope dengan metode ensemble Stacking. Pengambilan data menggunakan bantuan program yang telah dirancang untuk membaca sensor accelerometer dan gyroscope pada smartphone android yang diletakkan pada bagian kaki kanan manusia dengan durasi waktu \pm 12 detik. Data berupa koordinat $\mathrm{x}, \mathrm{y}, \mathrm{z}$ dari sensor accelerometer dan gyroscope. Data akan diolah menggunakan metode ensemble Stacking untuk melakukan klasifikasi aktivitas manusia. Kemudian, akan dibandingkan dengan metode tunggal SVM untuk melihat akurasi, sensitivitas, dan spesifisitas dari metode yang diusulkan. Hasil menunjukkan bahwa kinerja metode ensemble Stacking mencapai kinerja dengan akurasi 99.2\%, sensitivitas $99.6 \%$ dan spesifisitas 98.7\%. Hasil kinerja metode ensemble Stacking berhasil meningkatkan akurasi dan sensitifity serta menurunkan specifity. 


\section{Daftar Pustaka}

Su, Xing, Hanghang Tong, and Ping Ji. "Activity recognition with smartphone sensors." Tsinghua science and technology 19.3 (2014): 235-249.

Chen, Ming-Syan, Jiawei Han, and Philip S. Yu. "Data mining: an overview from a database perspective." IEEE Transactions on Knowledge and data Engineering 8.6 (1996): 866-883.

Kaghyan, Sahak, and Hakob Sarukhanyan. "Activity recognition using k-nearest neighbor algorithm on smartphone with tri-axial accelerometer." International Journal of Informatics Models and Analysis (IJIMA), ITHEA International Scientific Society, Bulgaria 1 (2012): 146-156.

Putra, Suryadi, Istianah Muslim, and Muhammad Ihsan Zul. "Identifikasi Aktifitas Manusia di dalam Ruangan Menggunakan IP Camera dengan Metode Template Matching dan Algoritma Klasifikasi." 4th Applied Business and Engineering Conference. 2016.

Zubair, Muhammad, Kibong Song, and Changwoo Yoon. "Human activity recognition using wearable accelerometer sensors." 2016 IEEE International Conference on Consumer Electronics-Asia (ICCE-Asia). IEEE, 2016.

Agus Setiyandi. (2016). "Pengenalan Pergerakan Aktivitas Manusia Berbasis Sensor Accelerometer Dan Gyroscope Menggunakan Algoritma K-Means” 2016.

Rahmah, Fadhilatur, Hurriyatul Fitriyah, and Issa Arwani. "Sistem Klasifikasi Aktivitas Manusia Menggunakan Sensor Accelerometer Dan Gyroscope Dengan Metode K-Nearest Neighbor Berbasis Arduino." Jurnal Pengembangan Teknologi Informasi dan Ilmu Komputer e-ISSN 2548 (2018): 964X.

Hardiyanti, Nurul, Armin Lawi, and Firman Aziz. "Classification of Human Activity based on Sensor Accelerometer and Gyroscope Using Ensemble SVM method." 2018 2nd East Indonesia Conference on Computer and Information Technology (EIConCIT). IEEE, 2018.

Lawi, A., F. Aziz, and S. L. Wungo. "Increasing accuracy of classification physical activity based on smartphone using ensemble logistic regression with boosting method." Journal of Physics: Conference Series. Vol. 1341. No. 4. IOP Publishing, 2019.

Tinder, Richard F. "Relativistic flight mechanics and space travel." Synthesis lectures on engineering 1.1 (2006): 1-140.

Rindler, Wolfgang. Essential relativity: special, general, and cosmological. Springer Science \& Business Media, 2012.

Kabai, Sandor. "Oldham coupling, The Wolfram Demonstrations Project." (2008).

Cortes, Corinna, and Vladimir Vapnik. "Support-vector networks." Machine learning 20.3 (1995): 273-297.

Polikar, Robi. "Ensemble learning." Ensemble machine learning. Springer, Boston, MA, 2012. $1-34$.

Kuncheva, Ludmila I. Combining pattern classifiers: methods and algorithms. John Wiley \& Sons, 2014.

Wolpert, David H. "Stacked generalization." Neural networks 5.2 (1992): 241-259.

Provost, Foster, and Ron Kohavi. "Guest editors' introduction: On applied research in machine learning." Machine learning 30.2-3 (1998): 127-132. 